\title{
TRABALHO DECENTE E EMPREGO VERDE: UMA ANÁLISE À LUZ DO CARÁTER PLURIDIMENSIONAL DA SUSTENTABILIDADE
}

\section{DECENT WORK AND GREEN EMPLOYMENT: AN ANALYSIS BASED ON PLURIDIMENSIONAL CHARACTER OF SUSTAINABILITY}

\author{
${ }^{1}$ Flavia de Paiva Medeiros de Oliveira
}

${ }^{2}$ Maria Aurea Baroni Cecato

\section{RESUMO}

O princípio do desenvolvimento sustentável tem por finalidade garantir a compatibilidade do desenvolvimento econômico com a preservação dos recursos naturais para as presentes e futuras gerações. Concretiza-se na vida cotidiana através da sustentabilidade, que precisa ser encarada de forma ampla. $\mathrm{O}$ objetivo do presente trabalho é analisar os programas empregos verdes e trabalho decente da OIT à luz do caráter pluridimensional da sustentabilidade com vistas a caracterizar como verde apenas os postos de trabalho que sejam, ao mesmo tempo, sustentáveis do ponto de vista ambiental e social, já que esse critério identifica amplamente o homem com o seu entorno.

Palavras-chave: sustentabilidade; trabalho decente; empregos verdes; programas da OIT.

\begin{abstract}
The principle of sustainable development has the purpose of ensure compatibility between the economic development and the preservation of natural resources for presents and futures generations. It's concretized in everyday life by sustainability, that needs to be broadly considered. The objective of this work is to analyze the green employment and decent work's programs developed by ILO based on pluridimensional character of sustainability with a view to characterizing as green only the work stations that are, at the same time, sustainables from ambiental and social points of view, considering that this criterion broadly identifies the man with his surround.
\end{abstract}

Keywords: Sustainability; decent work; green employment; ILO’s programs.

\footnotetext{
${ }^{1}$ Doutorado em Direito do Trabalho e Previdência Social pela Universitat de València - UV (Espanha). Professor pela Universidade Estadual da Paraíba - UEPB, Paraíba (Brasil). E-mail: flaviadepaiva@ @otmail.com

${ }^{2}$ Doutorado em Direito do Trabalho pela Université de Paris II Panthéon Assas - PARIS 2 (França). Professor pelo Centro Universitário de João Pessoa - UNIPÊ, Paraíba (Brasil).

E-mail: mariaaurea.cecato@gmail.com
} 


\section{Considerações iniciais}

O princípio do desenvolvimento sustentável ganhou eco a partir da Conferência de Estocolmo e estabeleceu um padrão de respeito ao meio ambiente, que propugnou pelo atendimento das necessidades das gerações presentes, garantindo-se, também, às gerações futuras a concretização de suas aspirações. Esse princípio tem por finalidade compatibilizar o processo de desenvolvimento econômico com a preservação dos recursos naturais com vistas a garantir a vida no Planeta Terra.

É certo que o seu conteúdo, ao longo do tempo, sofreu aprimoramentos. Não obstante, mantém um núcleo constante e imutável que consiste na necessidade de buscar sempre alcançar um equilíbrio, dando ao homem do presente a obrigação de garantir uma relação equilibrada com o seu entorno, tanto para resguardar a sua própria vida, quanta a vida das gerações vindouras. Essa busca pelo equilíbrio que permeia a relação do ser humano com o seu entorno faz com que seja necessário encontrar mecanismos reais que devem estar presentes no cotidiano da espécie humana. Tais medidas diárias de busca pelo equilíbrio constituem a sustentabilidade. Ter uma postura sustentável significa, portanto, buscar cotidianamente uma relação equilibrada com o entorno. Por essa razão, a sustentabilidade deve ser encarada sob um viés pluridimensional, a fim de permitir que esse equilíbrio se estenda a todos os âmbitos da vida humana.

O trabalho é um aspecto da vida do homem de notória importância, porque, além de garantir ao trabalhador auferir os recursos indispensáveis a sua subsistência, lhe confere identidade social e deve também permitir a identidade daquele que trabalha com o seu entorno. É nesse contexto que surgem os empregos verdes, considerados como tais aqueles postos de trabalho que geram uma menor danosidade ao meio ambiente, na medida em que geram baixas emissões de carbono.

O objetivo do presente trabalho é demonstrar que os postos de trabalho verdes, ademais de viabilizarem a preservação dos recursos naturais, devem também garantir condições de trabalho decentes.

Para tanto, far-se-á uma análise do viés pluridimensional da sustentabilidade, bem como dos programas da OIT que versam sobre o trabalho decente e o emprego verde, a fim de demonstrar, em primeiro lugar, que nem todo emprego verde é decente, mas que há mecanismos jurídicos capazes de fazer com que o emprego verde seja também considerado como trabalho 
decente, tendo em vista que a conjugação desses dois fatores concretiza a sustentabilidade ambiental e social.

\section{A sustentabilidade e suas dimensões}

O ponto de partida para o despertamento acerca de uma conscientização ecológica foi, inequivocamente, dado com a Conferência de Estocolmo em 1972, que chamou a atenção para a importância da cooperação internacional nos assuntos relacionados ao meio ambiente (COMPAGNONI, s/d). A partir dela, percebeu-se a nível internacional que havia um problema que assolava separadamente, em maior ou menor escala, a todos os países do Planeta Terra cujas proporções não podiam ser avaliadas individualmente por cada membro da comunidade internacional, mas tinha que ser visto sob uma perspectiva global.

Segundo Le Prestre (2000), a conferência foi realizada para atender quatro fatores que influenciaram a sociedade ambiental da época: aumento e importância da comunidade científica, que começavam a questionar sobre o futuro do planeta; as mudanças climáticas e sobre a quantidade e qualidade da água; aumento da exposição, pela mídia, de desastres ambientais (marés negras, desaparecimento de territórios selvagens, modificações na paisagem), gerando um maior questionamento da sociedade acerca das causas e soluções para tais desastres; crescimento desenfreado da economia, e consequentemente das cidades, sendo que estas cresceram sem nenhum planejamento para o futuro; outros problemas ambientais, como chuvas-ácidas, poluição do Mar Báltico, grandes quantidades de metais pesados e pesticidas.

O fruto desse encontro internacional foi a elaboração de um arcabouço jurídico de proteção ao meio ambiente com a enunciação de princípios que, posteriormente, foram plasmados nas Constituições que entraram em vigor a partir de então e serviram para fazer nascer a ideia de que a preservação do meio ambiente deve ser uma preocupação não só dos Estados, mas também da sociedade, criando, destarte, a ideia de responsabilidade coletiva para com os recursos naturais.

A Organização das Nações Unidas (ONU) se posicionou formalmente sobre a sustentabilidade, em 1987, no Relatório "Nosso Futuro Comum", no qual se recomendou a realização de uma conferência mundial para tratar da questão ambiental, a Rio-92. Nesse relatório, afirmou-se o seguinte: 


\begin{abstract}
Muitos de nós vivemos além dos recursos ecológicos, por exemplo, em nossos padrões de consumo de energia. No mínimo, o desenvolvimento sustentável não deve pôr em risco os sistemas naturais que sustentam a vida na Terra: a atmosfera, as águas, os solos e os seres vivos. Na sua essência, o desenvolvimento sustentável é um processo de mudança no qual a exploração dos recursos, o direcionamento dos investimentos, a orientação do desenvolvimento tecnológico e a mudança institucional estão em harmonia e reforçam o atual e futuro potencial para satisfazer as aspirações e necessidades humanas. (ONU, 1991, p. 49).
\end{abstract}

Desde o mencionado relatório até o momento presente, é certo que o conceito em análise vem sofrendo aprimoramentos. Todavia, a sua essência não se desnaturou e mantém-se relacionada ao equilíbrio entre a satisfação de necessidades presentes e a viabilidade de existência das gerações futuras. Essa ideia de sustentabilidade nascida no final do século XX deixou claro a falência do modelo de crescimento econômico adotado até então e evidenciou que ele não era capaz de garantir o desenvolvimento qualitativo do ser humano (COELHO; ARAÚJO, s/d).

Partindo de tais premissas, é possível dizer, portanto, que o desenvolvimento sustentável é um modelo de desenvolvimento que reconhece a necessidade de aliar crescimento econômico à preservação dos recursos ambientais e encontra na sustentabilidade um meio para a sua concretização na vida diária do indivíduo, já que, por meio dela, se buscam alternativas viáveis, ambientalmente corretas e socialmente justas para a construção de uma sociedade. Tendo em vista que a sustentabilidade concretiza o modelo de desenvolvimento sustentável, mister que ela seja encarada sob uma perspectiva sistêmica, que a analise sob o viés social, econômico, cultural, político e ambiental.

Nesse sentido, FIORILLO e DIAFÉRIA (1999, p. 31) argumentam que:

Tem por conteúdo a manutenção das bases vitais da produção e reprodução do homem e de suas atividades, garantindo igualmente uma relação satisfatória entre os homens e destes com o seu ambiente, para que as futuras gerações também tenham oportunidade de desfrutar os mesmos recursos que temos hoje à nossa disposição.

Do ponto de vista econômico, caracteriza-se como sendo a busca pelo equilíbrio entre a utilização de recursos naturais e a produção de riquezas. Sob a perspectiva política, impõe a adoção de políticas que impliquem em benefícios coletivos para a sociedade presente e futura. No aspecto social, a sustentabilidade consiste no modo de convívio social no qual a liberdade, a segurança, o bem-estar, o desenvolvimento, a igualdade, e a justiça constituem os valores capazes de efetivar uma sociedade solidária e participativa, preocupada e atenta para o bem-estar, não só das presentes, mas das futuras gerações. A finalidade de se propugnar por tal vertente da sustentabilidade é garantir que o desenvolvimento ocorrerá de forma equilibrada a 
promover, não apenas a preservação dos recursos naturais, como também a inclusão social com participação democrática dos sujeitos envolvidos nos processos decisórios. $\mathrm{O}$ aspecto cultural impõe a compreensão e o respeito mútuo entre as diversas culturas nacionais, blocos comunitários e bases civilizacionais. Na concepção ambiental, a ideia de sustentabilidade traz à tona a preservação dos recursos naturais para as presentes e futuras gerações. Sustentável, portanto, é algo que se mantém equilibrado ao longo do tempo sob uma perspectiva dinâmica, pluridimensional e coletiva. (COELHO; ARAUJO, s/d).

Essa noção pluridimensional da sustentabilidade tem como ponto de partida a superação do paradigma de dominação do homem sobre a natureza, que passa a encará-lo como parte do meio ambiente, pelo que se impõe o respeito e o cuidado do ser humano para consigo mesmo e para com o próximo, instituindo um padrão de ética fundamentada na alteridade, isto é, uma ética ambiental cujo alicerce é a responsabilidade, o cuidado e o respeito do homem para consigo mesmo, para com o próximo, para com as outras espécies e, até mesmo, para com os demais componentes abióticos que constituem a biosfera (NALINI, 2015, p. 45).

No texto do art. 225, da Constituição de 1988 (CF/1988), o legislador constituinte destacou a responsabilidade coletiva pela concretização da sustentabilidade sob a perspectiva sistêmica, ao reconhecer que é dever de toda a coletividade defender e preservar o meio ambiente para as presentes e futuras e gerações.

No âmbito do ordenamento jurídico, essa concepção pluridimensional da sustentabilidade encontra fundamento quando o art. 170, da CF/1988, reconhece que a livre iniciativa é um dos fundamentos da ordem econômica e que deve servir como fator capaz de assegurar a todos existência digna cuja consecução se concretiza através da preservação do meio ambiente. Ademais, é importante destacar que, ao lado da livre iniciativa e, até mesmo antes dela, figura também como fundamento da ordem econômica a valorização do trabalho humano. O trabalho, além de funcionar como um fundamento da ordem econômica, ao vir citado no texto constitucional antes da livre iniciativa, deve ser encarado como um dos objetivos que deverá ser alcançado por ela e passa a integrar a dimensão social da sustentabilidade na medida em que, quando realizado de forma digna, ou seja, decente, promove o bem-estar do ser humano. 


\section{Trabalho decente: um pressuposto para o emprego verde}

A expressão trabalho decente ${ }^{3}$, ou trabalho digno, passou a ser utilizada, ao final da década de 1980, a partir de proposta da OIT, com o fito de estabelecer uma agenda para a luta pela dignidade no trabalho. A agenda, que teve em seu cerne o trabalho decente, marcou, no nível internacional, a abertura de um debate e a realização de estudos, a proposta de convenções internacionais e o planejamento de ações e de assistência técnica aos Estados membros, aí incluída a aprovação de uma Declaração Internacional (sobre a justiça social para uma globalização equânime - ONU, 2008). A expressão trabalho decente indica, portanto, o conjunto das ações da OIT, com a participação dos Estados membros, no intento de expandir e fortalecer, em âmbito mundial, a compreensão da necessidade de decência na atividade antrópica mais relevante.

Dos estudos da OIT partiu o entendimento de que o trabalho decente deve ser assentado sobre quatro eixos principais: a existência de trabalho enquanto ocupação; o respeito à regulamentação das relações laborais; a proteção social e o diálogo social.

A existência de emprego encabeça o grupo dos quatro pilares com uma explicação inarredável: seria pouco justificável tratar da decência no trabalho sem, a priori, incluir nesse rol de questões maiores que atinem à dignidade laboral, a existência do próprio trabalho enquanto ocupação, visto que é a partir desta que os demais pilares podem ser avaliados.

Entretanto, conquanto possa parecer redundante, há que se considerar que admitir a existência de postos de trabalho, independentemente de sua qualidade, implicaria na perda dos propósitos da agenda do trabalho decente. Há que se contar, portanto, com empregos onde estejam garantidos os demais pilares acima relacionados. Em outros termos, não há que se valorizar a existência de um posto de trabalho no qual não se verifica o respeito aos direitos laborais.

No rol dos eixos que esteiam o trabalho decente, a OIT, na seqüência da existência de emprego, prestigiou o atendimento às disposições que regulamentam as relações de trabalho. Ao menos no Ocidente - e mesmo em alguns países do Oriente - seguiu-se o padrão do constitucionalismo social, de forma que, nesses países, conta-se com um rol de direitos fundamentais que em conjunto com os direitos infra-constitucionais, formam um arcabouço

\footnotetext{
${ }^{3}$ Considerando o senso comum do termo, decente refere-se àquilo que é conforme aos "[...] padrões morais e éticos da sociedade"; "[...] honrado, honesto"; "[...] digno, correto, decoroso". (HOUAISS, 2003).
} 
capaz de garantir proteção mínima para o trabalhador ${ }^{4}$. Em geral, os Estados membros da OIT cuidaram também de garantir a tutela jurisdicional como complemento às normas substantivas.

O diálogo social diz respeito ao espaço político que o trabalhador, coletivamente organizado, pode ocupar enquanto um dos atores que definem as políticas e ações que interessam diretamente a ao grupo do qual faz parte. Mais especificamente, no caso dos trabalhadores, tais diálogos referem-se às discussões que se passam nos fóruns dos quais participam, através de seus representantes. ${ }^{5} \mathrm{O}$ que mais diretamente interessa ao trabalhador é o próprio sindicato, vez que ali se passam as negociações que criam direitos e obrigações para as categorias econômica e profissional.

Em todos os casos de representação dos trabalhadores dois elementos são relevantes: um é o regime democrático, até porque as negociações sindicais são, em geral, prerrogativas de regimes abertos. O outro é a liberdade sindical. Também incomum em regimes autoritários, ela é igualmente relevante, posto que a ausência ou limitações da liberdade de constituição ou ação sindical reduz igualmente as condições do poder de barganha do coletivo de trabalhadores, submetendo-o à vontade, seja do patronato, seja do Estado.

No caso do Brasil, uma observação deve ser feita: a liberdade sindical é limitada. Todavia, conquanto permanecendo aquém do padrão defendido internacionalmente, notadamente no âmbito da OIT e, malgrado a persistência do Brasil em não ratificar a Convenção $n^{\circ} 87$, sobre liberdade sindical, o texto constitucional de 1988 registra um avanço significativo no sentido da liberdade.

A proteção social - mais um dos pilares do trabalho decente anotado nos estudos OIT - se configura como extensão da proteção atribuída às relações laborais. Com efeito, a proteção social não foi pensada especificamente para os trabalhadores, porque sempre se apresentou como necessidade de qualquer ser humano. Aliás, a História registra, ao longo de seu percurso, e nos inúmeros pontos do planeta, a existência de medidas de apoio e assistência aos menos favorecidos, inicialmente resultantes de iniciativas privadas ou religiosas, destinadas a todos que delas necessitassem.

\footnotetext{
${ }^{4}$ Referindo valores dentre os quais se incluem o "fazer valer a justiça social" e o "preservar a dignidade humana", Souto Maior e Correia (2007, p. 27-28) asseveram a importância da regulação do trabalho "[...] porque a organização social pressuposta é proveniente de um modelo determinado, qual seja, o capitalismo, que se impulsiona pela produção de riquezas a partir do trabalho, sobretudo do trabalho alheio".

${ }^{5}$ No Brasil os trabalhadores são representados em diversos fóruns, a exemplo o Conselho Curador do Fundo de Garantia do Tempo de Serviço.
} 
De toda sorte, a relevância da proteção social para o trabalho decente é notória. Com efeito, ultrapassando os limites das relações de trabalho, os benefícios por ela aportados - sejam os de ordem previdenciária, sejam os de natureza assistencial, se estendem para a vida do trabalhador, destinando-se não só a ele próprio, mesmo fora do ambiente de trabalho, mas também como às pessoas que dele dependem. Dessa forma, proporciona condições para que o labor seja melhor realizado, na medida em que traz, para o trabalhador, segurança, conforto e tranquilidade ${ }^{6}$.

De outro lado, na medida em que a proteção social assegura condições para que o prestador de serviços se mantenha produzindo, garante ao tomador de serviços um ponto de distensão na gestão do seu empreendimento. (IPEA, 2010).

É também esse o objetivo (acrescido de outros, como se verá a seguir) do investimento que vem sendo feito pela OIT no sentido da criação de empregos verdes. Mais que isso, o emprego verde, segundo a Organização, se traduz por um posto de trabalho que está inserido em um empreendimento eficiente, voltado para um funcionamento preocupado com a preservação do meio ambiente. Reconhece-se que esses empregos podem estar "[...] apenas substituindo alguns postos de trabalho já existentes." Todavia, deve-se levar em conta que nesses casos a mão-de-obra é mais intensamente utilizada nas tecnologias "limpas", de forma que a “[...] mudança nos padrões de produção e consumo de bens e serviços dificilmente deixará de proporcionar algum ganho líquido na oferta total de emprego.” (ALVAREZ; MOTA, 2010, p. 624).

O empenho da OIT na criação e desenvolvimento do Programa Empregos Verdes prende-se a alguns fatores. Dentre eles, parecem ser os mais relevantes: a existência, em todo o mundo, de um grande contingente de trabalhadores migrantes (em torno de cento e cinquenta milhões) por razão das mudanças climáticas; a necessidade de empregos para todos e, por último, a necessidade de melhorar a qualidade das condições de trabalho, tornando os empregos decentes (OIT, 2016). A esse propósito, há que se fazer referência ao investimento da OIT, ao longo dos últimos vinte anos, na agenda do trabalho decente.

Acredita-se que um Programa dessa natureza tenha um especial potencial para a criação de empregos. Por outro ângulo, acredita-se ser possível manter a qualidade desses empregos (mais que em qualquer outra situação) dado o fato de que deverá haver uma vigilância

\footnotetext{
${ }^{6}$ Veja-se, a propósito, o texto: BOSCHETTI (2003).
} 
sobre as empresas que aderirem ao Programa, porque estarão também engajadas na economia verde, ou seja, na produção com baixa emissão de carbono ${ }^{7}$.

Em suma, os empregos verdes devem poder contribuir para a proteção do meio ambiente, para o desenvolvimento econômico e para a inclusão social, envolvendo governos, trabalhadores e empregadores em um projeto que traz resultados ambientais e sociais incomparáveis (OIT, 2016).

\section{Empregos verde: uma consequência da sustentabilidade sob a perspectiva ambiental e social.}

A necessidade de gerar empregos verdes surge como uma consequência do princípio da sustentabilidade, bem como do reconhecimento constitucional de que a ordem econômica, que encontra seu fundamento no art. 170, da CF/1988, tem como alicerce a valorização do trabalho humano para promover existência digna, através da preservação do meio ambiente. Essa necessidade não consiste, todavia, apenas em uma padrão axiológico observado a nível interno. Ao contrário, trata-se de uma preocupação internacional que foi enfrentada pela Organização Internacional do Trabalho (OIT), através do Relatório Empregos Verdes (OIT, 2008), que decorreu de uma parceria entre o Programa das Nações Unidas para o Meio Ambiente (PNUMA), a OIT, a Confederação Sindical Internacional (CSI) e a Organização Internacional de Empregadores (OIE).

Nesse relatório, os empregos verdes são considerados como "aqueles que reduzem o impacto ambiental de empresas e de setores econômicos para níveis que, em última análise, sejam sustentáveis" (OIT, 2008, p. 5). Esses postos de trabalho podem ser encontrados nos mais variados setores da economia, desde a agricultura, indústria, serviços até o setor de administração. O pressuposto para ser considerado como tal é de que ele contribua para a preservação ou restauração da qualidade ambiental.

\footnotetext{
${ }^{7}$ O desenvolvimento do Programa empregos verdes está sendo assistido, pela OIT, em mais de 30 países em desenvolvimento (inclusive o Brasil). A assistência presta-se, dentre outras possibilidades a: propor programas de formação nos níveis internacionais, regionais e nacionais em colaboração com a unidade de formação sobre empregos verdes do CIF-OIT (Centro Internacional de Formação da OIT); elaborar diagnóstico e estabelecer priorizações identificando os sectores econômicos que desdrutam de elevado potencial para empregos verdes e orientar a formulação e execução de políticas eficazes nos níveis nacional e setorial para a criação de empregos verdes. (Informações obtidas segundo a referência OIT, 2016).
} 
Tais empregos se espraiam por diversos setores, tais como, fontes renováveis de energia (fornecimento de energia), no qual foram gerados mais de 2,3 (dois, três) milhões de empregos ${ }^{8}$; construção civil; meios de transporte, tendo sido criados 5 (cinco) milhões de empregos só em ferrovias na China, Índia e União Europeia; industrias básicas e de reciclagem que garantem 12 (doze) milhões de empregos no Brasil, China e Estados Unidos; agricultura, que continua sendo o setor mais expressivo para o crescimento dos empregos verdes, empregando 1,3 (um, três) bilhão de produtores rurais e trabalhadores agrícolas. Nesse setor, a agricultura orgânica é o carro chefe a ponto de, no ano de 2006, ter movimentado 100 (cem) bilhões de dólares no mercado mundial; florestas, para esse setor se reconhece a escassez de dados para precisar números (OIT, 2008, p. 5-13).

O estudo desses tipos de empregos, bem como a adoção de políticas públicas capazes de fomentá-los, representa um esforço para superar um duplo desafio do século XXI. De um lado, a proteção do meio ambiente natural. De outro, a necessidade de garantir trabalho decente, bem-estar e dignidade para todos em um contexto mundial no qual mais de um bilhão de pessoas estão excluídas do desenvolvimento econômico e social. Representa, portanto, uma conjugação da dimensão ambiental e social do princípio do desenvolvimento sustentável.

O relatório mencionado reconhece que a sustentabilidade vai além do seu caráter de preservação dos recursos naturais para adentrar na análise do ambiente laboral e das transformações no mundo do trabalho. Em 2012, a OIT reconheceu o caráter contínuo do conceito de empregos verdes e de que o seu constante aperfeiçoamento conduz a uma "economia verde" (OIT, 2012). Reiterou, ainda, que a ideia de economia verde não se centra apenas na proteção dos recursos naturais. Ao revés, deve ter por base também uma discussão sobre os aspectos sociais dessa nova modalidade de postos de trabalho.

\footnotetext{
Una reorientación hacia economía verde supone un cambio radical en el paradigma de desarrollo generalmente admitido, que exige, a su vez, un amplio apoyo social. A diferencia de «revoluciones» anteriores, en esta ocasión, las medidas adoptadas en materia de política no pueden ser de naturaleza puramente tecnológica o económica. Mejorar el bienestar de la población mundial debe formar parte integrante del proceso encaminado a lograr el desarrollo sostenible. Este cambio de paradigma supone que, si bien deben controlarse los riesgos medioambientales, es preciso aumentar la equidad social y el bienestar de la humanidad (OIT, 2012, p. 3).
}

Essa ideia tão claramente defendida pela OIT e que atribui à sustentabilidade um viés nitidamente social como condição intrínseca para a emancipação da pessoa humana se alinha à

\footnotetext{
${ }^{8}$ Só no Brasil, foram gerados 500.000 empregos verdes no setor da biomassa (OIT, 2008, p. 8).
} 
ideia defendida por Sen (2010, p. 55) de ver o desenvolvimento como um processo de expansão das liberdades reais que o ser humano desfruta.

Nesse sentido, Cruz e Bodnar (2013, p. 51) destacam o caráter unificador da sustentabilidade e asseveram que ela "importa em transformação social, sendo conceito integrador e unificante, isso implica na celebração da unidade ser humano e natureza, na origem e no destino comum".

É justamente esse caráter unificador e integrador da sustentabilidade que a OIT faz questão de relevar quando analisa o emprego verde sob a perspectiva do trabalho decente, que, sob o aspecto prático, demanda uma avaliação desses empregos sob o prisma da segurança e saúde dos trabalhadores. Isso, porque essa nova modalidade de trabalho acarreta riscos laborais novos e emergentes, com relação aos quais os estudos científicos estão na sua fase inicial, de modo que a sustentabilidade em seu caráter amplo requer empregos que, além de gerarem uma baixa emissão de carbono no meio ambiente, garanta postos de trabalho seguros e saudáveis para os trabalhadores (OIT, 2012, p. 3).

O desafio, portanto, desses novos postos de trabalho verdes não se limita apenas à preservação da natureza, dos recursos naturais e dos ecossistemas, mas à preservação da pessoa trabalhadora em sua inteireza, começando por lhe garantir emancipação social. A finalidade é fomentar uma integração do trabalhador, dos recursos utilizados para o trabalho, do próprio empreendimento com os recursos naturais e os ecossistemas, mas também alcançar o resguardo da integridade física e moral da pessoa trabalhadora.

A superação desse desafio se mostra importante, mormente quando se analisam os empregos verdes gerados no setor da reciclagem, cuja criação decorreu, em sua grande maioria, de iniciativas comunitárias e individuais, nas quais a preocupação com a saúde dos trabalhadores foi deixada de lado, pelo que não se pode qualificar tais trabalhos como decentes, pelo simples fato de serem verdes (OIT, 2008, p. 12).

Isso porque o fato de um trabalho ser verde, do ponto de vista da dimensão ambiental da sustentabilidade, não implica necessariamente que ele será verde, sob a perspectiva social, especificamente, sob o viés da salubridade do meio ambiente de trabalho. Por isso, a OIT chama atenção para o perigo que existe em designar um emprego como verde, partindo, para tanto, somente de uma avaliação da sustentabilidade ambiental:

Sin embargo, existe el riesgo de que en el proceso de creación de empleos verdes se pasen por alto riesgos laborales nuevos y emergentes. La reciente inversión en tecnología ecológica para crear «empleos verdes» ha suscitado preocupación debido 


\begin{abstract}
a la escasa atención prestada a los riesgos laborales que existen en tales empleos y, por tanto, a la necesidad de integrar medidas de seguridad y salud en la concepción de los empleos verdes. Aunque algunos empleos se consideren «verdes», las tecnologías utilizadas tal vez no sean «verdes» en absoluto. Si bien, en general, las tecnologías «verdes» probablemente reduzcan el riesgo de una exposición peligrosa para el medio ambiente, dichos cambios deben examinarse con detenimiento antes de ponerse en práctica. La sustitución de algunas sustancias peligrosas para el medio ambiente por unas sustancias más ecológicas ha demostrado ser más peligroso para la salud de los trabajadores. Por ejemplo, la sustitución de pinturas al disolvente por pinturas al agua ha incluido la adición de biocidas. La sustitución de hidroclorofluorcarburos por clorofluorocarburos ha aumentado el riesgo de exposición a carcinógenos, así como a peligros de incendio (OIT, 2012, p. 4).
\end{abstract}

Assim sendo, atribuir a um trabalho a tonalidade verde, segundo a OIT, significa, ao mesmo tempo, dizer que o posto de trabalho é sustentável sob a perspectiva ambiental e social, sendo capaz de garantir a integridade do meio ambiente e da pessoa trabalhadora, sendo esse o elemento central em torno do qual a questão deve ser discutida. O desafio, portanto, consiste em tornar os postos de trabalho verdes sustentáveis do ponto de vista ambiental e social.

\title{
4 Concretizando a sustentabilidade ambiental e social: como fazer de um emprego verde um trabalho decente
}

Atento ao fato de que a sustentabilidade deve ser analisada sob uma perspectiva ampla, que a considera sob o viés econômico, político, social, cultural e ambiental equilibrado, com vistas a atender às necessidades das gerações presentes sem comprometer as capacidades das gerações futuras (COELHO; ARAÚJO, s/d), mister pensar em medidas capazes de promover um esverdeamento real dos postos de trabalho que tendem a surgir com o crescimento da economia verde.

Um emprego verde não necessariamente implica em um trabalho decente sob o ponto de vista da proteção social e da integridade física e moral do trabalhador que o realiza. Nesse sentido, a própria OIT (2012a, p. 134-135) tem chamado a atenção para certos modalidades de emprego que, embora promovam a sustentabilidade ambiental, não são capazes do fomentá-las do ponto de vista social. Um dos setores em que essa preocupação avulta de maneira mais forte é o da reciclagem de materiais, vez que nesse setor a informalidade em que o trabalho é desenvolvido é mais marcante, o que dificulta a formação e capacitação profissional e a fiscalização no que concerne ao cumprimento das normas de saúde e segurança do trabalho.

Imprescindível se torna, portanto, analisar e discutir possíveis medidas que poderão ser adotadas para que a sustentabilidade alcance o seu máximo grau de concretização. 
A primeira dessas medidas diz respeito à avaliação dos riscos que o empreendimento verde irá gerar. Essa avaliação, ademais de prever os riscos que o empreendimento causa para o entorno natural, deverá contemplar também os riscos sociais, tanto para a população da área onde o empreendimento será instalado, quanto os riscos laborais, que alcançam especificamente os trabalhadores.

Quando se trata de empreendimentos novos, um grande aliado para a determinação desses riscos de forma mais segura, são os estudos ambientais com especial destaque para a Análise Preliminar de Risco (APR), prevista pelo art. 1º, III, da Resolução Conama nº 237/1997, que é tida, pelos profissionais da área de segurança do trabalho, como um estudo antecipado e detalhado de todas as fases do trabalho, a fim de detectar os possíveis problemas que poderão acontecer durante a sua execução, para que se adotem as medidas necessárias à neutralização dos riscos, criando, assim, um ambiente de trabalho seguro. De acordo com a norma mencionada, esse estudo é um dos que poderá ser exigido pelo órgão responsável pelo licenciamento ambiental como requisito para a concessão da licença de empreendimentos novos.

A avaliação dos riscos ambientais e sociais que essa modalidade de emprego suscita é de grande importância para promover a formação e capacitação do trabalhador que irá laborar nessas novas espécies de empreendimentos, sobretudo, para que eles possam ter acesso a postos de trabalho que lhe garantam um programa preventivo de riscos laborais que seja consentâneo com a realidade do ambiente laboral.

Todavia, um questionamento importante deve ser feito nesse ponto: E quando o empreendimento a ser avaliado for verde sob a perspectiva ambiental, mas não for capaz de afrontar satisfatoriamente os riscos laborais, não contemplando uma adequada estratégia preventiva, expondo seus trabalhadores a condições de trabalho que colocam em risco a sua saúde e segurança, acarretando um trabalho que não pode ser enquadrado como decente, como devem proceder nessa situação concreta os órgãos de fiscalização? A resposta para essa questão passa novamente pela análise do objetivo que a OIT pretende alcançar quando se dedica ao estudo dos empregos verdes.

Analisando esse tema, Held e Julio (s/d, p. 3) afirmam que é necessária a compreensão dos empregos verdes como trabalho decente, uma vez que eles estão intrinsecamente ligados ao desenvolvimento humano e ambiental sustentável.

Assim sendo, como existe uma indissociabilidade entre emprego verde e trabalho decente, como forma de concretizar a sustentabilidade no seu sentido amplo, imperioso chegar 
à conclusão de que, nos casos em que o empreendimento empregue práticas sustentáveis do ponto de vista ambiental, mas que não enseje medidas protetivas para a saúde e segurança do trabalhador, a atividade produtiva não deverá ser licenciada ou, quando já estiver em curso, deverá ser paralisada. Tal entendimento se coaduna com o princípio da prevenção cujo conteúdo impõe que se priorize as medidas que evitem o dano, reduzindo ou eliminando as suas causas, já que o dano ambiental, tanto na sua perspectiva estrita-de dano ao entorno natural, quanto sob o aspecto mais amplo-no qual se inclui o dano ao meio ambiente de trabalho, é irreparável (MACHADO, 2006, p. 36).

Outra medida relevante atine a formação profissional e à adequação de aptidões profissionais tradicionais a essa nova realidade verde, que exige novas técnicas de trabalho para as quais o trabalhador pode não estar preparado, a fim de evitar que haja uma excedência de postos de trabalho verdes vagos como consequência de um déficit de qualificação profissional específica ${ }^{9}$. Nesse sentido, a OIT destaca que:

La formación en el trabajo para afrontar los cambios en los procesos productivos será un elemento clave de la estrategia de competencias profesionales. Además, algunos trabajadores tal vez necesiten cambiar de sector, por ejemplo, a nuevas industrias sostenibles y, por lo tanto, es necesario ofrecer nueva formación y actualización de las capacidades profesionales para mejorar sus posibilidades de encontrar un nuevo empleo (OIT, 2012a, p. 188).

Com o crescente incremento dos postos de trabalho verdes, essa formação profissional específica deve, inclusive, ser utilizada para abreviar os tempos de espera do trabalhador desempregado nos programas de emprego. Para tanto, esse período de desemprego e de recebimento do auxílio social deve ser utilizado para promover essa capacitação profissional específica $^{10}$, evitando, assim, a deterioração das capacidades profissionais e melhorando a empregabilidade.

\footnotetext{
${ }^{9}$ Para exemplificar tal situação, a OIT (2012a,p. 190) cita os seguintes casos: "El sector de la energía eólica brinda un buen ejemplo de buenas prácticas en relación con la adaptación a la necesidad de nuevas competencias profesionales. A pesar de la escasez inicial de mano de obra, el sector de la energía eólica ha contratado empleados de otros sectores y luego les brindó una diversidad de programas de formación para solucionar la falta de trabajadores con capacidades profesionales específicas del sector (IIEL y EC, 2011b). En España, el Gobierno regional de Navarra logró convertir a la región -tradicional productora automotriz-en la sexta productora de energía eólica de Europa, y crear y proveer formación para más de 6.000 puestos de trabajo en el sector."

10 A OIT (2012a, p. 187) cita dois exemplos em que o período de recebimento de seguro-desemprego foram utilizados para a qualificação profissional específica: "el servicio público de empleo flamenco ha desarrollado un centro de competencias profesionales relacionadas con los edificios sostenibles en Flandes Oriental. Además de la formación sobre capacidades prácticas, como aprender a construir un sistema de calefacción ecoeficiente, el centro también intenta adaptar a los trabajadores y los ingenieros con cualificaciones en la construcción verde a las demandas del sector. De igual manera en Marruecos, el servicio público de empleo ANAPEC gestiona el proceso
} 
No entanto, o principal problema diz respeito à promoção de trabalho decente nos setores verdes em que o desenvolvimento das atividades laborais ocorrem de maneira informal, como é o caso da reciclagem de materiais. Isso ocorre porque tais atividades, realizadas de maneira informal, ensejam condições de trabalho perigosas ou insalubres cuja modificação não pode ser exigida de um empresário específico, vez que tais trabalhadores são autônomos, trabalhando por conta própria. Para tal fato, a OIT faz um alerta:

\begin{abstract}
Uno de los mayores desafíos que enfrentan los trabajadores del sector informal de la recuperación de material -especialmente los que trabajan directamente en los vertederos- son las condiciones laborales peligrosas. Dado que trabajan sin ningún tipo de protección, los recicladores están expuestos a una diversidad de toxinas e infecciones microbianas y parasitarias. Además, los ingresos generalmente son bajos e inestables. Por si fuera poco, los gobiernos municipales suelen considerar a los recolectores una molestia, y los amenazan o los persiguen. No hay otro sector de la economía que esté más necesitado de la implementación de iniciativas políticas para promover cierto grado de formalización y brindar beneficios de salud y seguridad, y formación adecuada (OIT, 2012a, p. 130).
\end{abstract}

A vulnerabilidade desse grupo de trabalhadores decorre do exercício isolado e individual da profissão. Destarte, para sanar essa lacuna é imprescindível fomentar o associativismo e o cooperativismo para que os recicladores e todos os demais coletivos de trabalhadores que laborem em trabalhos verdes informais realizem sua atividade laborativa coletivamente e de forma organizada. No caso específico dos recicladores, a organização coletiva permite que tais trabalhadores tenham uma maior possibilidade de negociação frente a intermediários e ainda permite que tais organizações sejam contratadas pelo Poder Público, bem como facilita a fiscalização dos órgãos de fiscalização do trabalho.

Ademais, essa organização coletiva de trabalhadores verdes informais permite que os órgãos de fiscalização ambiental e do trabalho possam cumprir o seu papel de fiscalização, tanto no que concerne ao respeito ao meio ambiente, quanto acerca das condições de trabalho e, principalmente, se tais atividades verdes informais não estão sendo realizadas por crianças.

O que resulta sobremaneira importante é que o associativismo e o cooperativismo operam um fortalecimento de tais trabalhadores informais, seja em relação à sociedade civil, seja em relação aos poderes públicos.Com respeito à primeira, torna tais trabalhadores visíveis para a sociedade, retirando-lhes de uma situação de trabalho pejorativo e lhes conferindo importância e identidade social. No que atine aos segundos, permite que os entes públicos

de contratación de personal para que la construcción eficiente de obras públicas a gran escala contribuya a mejorar la infraestructura en el país”. 
possam contratá-los e, no caso brasileiro especificamente, cumprir o previsto na Lei da Política Nacional de Resíduos Sólidos (Lei $\mathrm{n}^{\circ}$ 12.305/2010) que estabelece uma responsabilidade social e coletiva pela gestão de tais resíduos.

Os estudos realizados pela OIT (2012 e 2012a) mostram que o esverdeamento da economia é uma tendência real do século XXI. Não obstante, é necessário criar mecanismos e realizar estudos para que essa tendência gere também um desenvolvimento social com a diminuição da pobreza e permita uma distribuição equitativa dos benefícios gerados pelo crescimento econômico, porque só assim se alcançará uma concretização da sustentabilidade sob a perspectiva ambiental e social.

\section{Considerações finais}

O princípio do desenvolvimento sustentável tem como conteúdo garantir que as necessidades das gerações presentes sejam atendidas sem comprometer a oportunidade de satisfação das gerações futuras. Trata-se, portanto, de uma norma jurídica que compatibiliza progresso e preservação do ambiente. Não se pode, contudo, limitar o conteúdo desse princípio à compatibilização do progresso econômico com a preservação dos recursos naturais. Mister entender que o progresso que deve ser compatibilizado não é apenas o econômico, mas também o social, cultural e político com a obrigação coletiva de preservar o meio ambiente.

A preservação dos recursos naturais requer, indubitavelmente, que o ser humano alcance um patamar de desenvolvimento social, cultural e político capaz de entender que não é o dono da natureza, o senhor do Planeta, mas o seu protetor, o seu vigia, seu guardião. Portanto, não se pode estreitar a concepção do desenvolvimento sustentável. Ao contrário, deve-se ampliá-la para enxerga-la também sob o prisma social, cultural e político, garantindo que o homem se enxergue na natureza de forma ampla.

Um dos pressupostos do desenvolvimento social do homem é o trabalho, que é capaz de lhe garantir perspectivas de bem-estar e dignidade, na medida em que constrói identidades e permite ao trabalhador participar e contribuir para o desenvolvimento da sociedade, ao mesmo tempo que lhe permite atender às suas necessidades vitais básicas.

O trabalho também deve ser encarado como um vetor de preservação dos recursos naturais, já que a força de trabalho do ser humano não pode ser empregada para a degradação do meio ambiente. O trabalhador deve entender as peculiaridades do entorno produtivo onde realiza as suas atividades laborativas, mas também as vicissitudes do entorno natural que cerca 
o ambiente de trabalho. Assim, estar-se-á permitindo que o trabalhador se insira no meio ambiente, seja ele natural, ou produtivo, e, ao mesmo tempo, assuma o seu papel de guardião, protetor, vigia do entorno natural.

Nesse cenário, os empregos verdes aparecem como um instrumento capaz de garantir que o homem atenda às suas necessidades vitais básicas e cumpra o seu papel de protetor da natureza. Ademais, tais modalidades de emprego concretizam o princípio do desenvolvimento sustentável sob a perspectiva ambiental e social, ao afrontar, de uma só vez, um duplo problema dos dias atuais. O primeiro deles diz respeito à forma de realização da atividade laborativa, que deve ser desempenhada para evitar a degradação dos ecossistemas, preservando-os adequadamente para as gerações futuras. O segundo consiste em garantir que tais postos de trabalho velarão pela individualidade física e moral daquele que trabalha, respeitando a sustentabilidade social, que, no que toca especificamente ao trabalho, se expressa por meio da realização de um trabalho decente.

Um fator que deve ser considerado é o de que nem todo trabalho verde pode ser considerado decente, pelo simples fato de atender a padrões de sustentabilidade ambiental. Nesse sentido, é conveniente destacar que certas práticas sustentáveis do ponto de vista ambiental ensejam um maior risco para a saúde do trabalhador. Por exemplo, a substituição de pinturas que antes eram realizadas com solventes por pinturas feitas à base de água incluiu em sua técnica a utilização de biocidas, que ensejam uma maior exposição do organismo humano a agentes cancerígenos.

Desse exemplo, observa-se que impende tornar as práticas laborativas verdes, sob a perspectiva ambiental, também verdes sob o viés social. Para tanto, é imperioso que se atente para a avaliação dos riscos laborais que a prática verde pode gerar para a saúde do trabalhador, o que deve ser concretizado por meio de uma detalhada Análise Preliminar de Risco (APR), estudo ambiental que avalia os riscos laborais em todas as fases do trabalho.

Se houver conflito entre as perspectivas da sustentabilidade, ou seja, se um posto de trabalho for considerado verde, mas não ensejar trabalho decente, deve-se optar por não licenciá-lo, partindo-se para tanto do fundamento de que o dano ao meio ambiente, tanto do ponto vista natural, quanto da análise do ambiente de trabalho, é irreparável.

Ademais, urge garantir uma adequada formação e capacitação profissional, a fim de que profissionais, antes empregados em um labor tradicional, sejam treinados para a realização de um trabalho ecologicamente equilibrado e que atenda também a condições de higidez física e moral de seus trabalhadores. 
Por fim, convém incentivar o associativismo e o cooperativismo em determinados setores em que o emprego verde é realizado de maneira informal, com vistas a garantir que tais trabalhadores ganhem força perante terceiros com os quais irão contratar o fornecimento de seus produtos ou serviços, bem como para lhes dá visibilidade social lhes retirando de uma situação de trabalho pejorativo e lhes conferindo importância e identidade social.

O emprego verde, quando é desempenhado também de forma decente, permite uma maior identificação do ser humano, tanto com o seu meio natural, quanto com o meio social no qual ele vive, além de representar um benefício coletivo de proporções transfronteiriças, porque pode ser utilizado como fator de inclusão social para trabalhadores que se encontram em situação de pobreza, acarretando uma diminuição da pobreza e gerando inclusão.

\section{Referências bibliográficas}

ALVAREZ, A. R.; MOTA, J. A. (Org.). Sustentabilidade ambiental no Brasil: biodiversidade, economia e bem-estar humano. Novas perspectivas para a geração de empregos verdes no Brasil. Brasília: Ipea, 2010. Disponível em: http://www.ipea.gov.br/portal/images/stories/PDFs/livros/livros/livro07_ sustentabilidadeambienta.pdf. Acesso em: 16/08/2016.

BOSCHETTI, I. Implicações da reforma da previdência na seguridade social brasileira. In: Psicologia \& Sociedade, Florianópolis, v. 15, n. 1, p. 57-96, 2003.

BRASIL. IPEA. Brasil em Desenvolvimento: Estado, planejamento e políticas públicas. Brasília: Ipea, 2010. Disponível em: http://www.ipea.gov.br/bd/pdf/Livro_BD_vol2.pdf. Acesso em: 20/04/2016.

COELHO, S. de O. P.; ARAÚJO, A. F. G. de. A sustentabilidade como princípio constitucional sistêmico e sua relevância na efetivação interdisciplinar da ordem constitucional econômica e social: para além do ambientalismo e do desenvolvimentismo. Disponível em: https://mestrado.direito.ufg.br/up/14/o/artigo_prof_saulo.pdf. Acesso em: 03/03/2016.

COMPAGNONI, R. L. Empregos verdes como mecanismo de redução de impactos ambientais. Disponível em: http://www.ambito-juridico. com.br/site/index.php/?n_link=revista_artigos_leitura\&artigo_id=12423\&revista_caderno. Acesso em: 08/08/2016.

CRUZ, P. M.; BODNAR, Z. (Org.). Globalização, transnacionalidade e sustentabilidade. Itajaí: UNIVALI, 2012. Disponível em: http://www.univali.br/ppcj/ebook. Acesso em: 05/05/ 2013.

FIORILLO, C. A. P.; DIAFÉRIA, A. Biodiversidade e patrimônio genético no Direito Ambiental Brasileiro. São Paulo: Max Limonad. 1999. 
HELD, T. M. R.; JULIO, F. A. Empregos verdes: a concepção socioambiental de trabalho decente e a aplicação do princípio da justiça equitativa de oportunidades. Disponível em: http://www.publicadireito.com.br/artigos/?cod=daa172021eb0b28d. Acesso em: 08/12/2015.

HOUAISS, A. Dicionário Houaiss: sinônimos e antônimos. Rio de Janeiro: Objetiva, 2003.LE PRESTRE, P. Ecopolítica Internacional. São Paulo: Senac, 2000.

MACHADO, P. A. L. Direito Ambiental Brasileiro. 14 ed. São Paulo: Malheiros, 2006.

NALINI, J. R. Ética Ambiental. 4 ed. São Paulo: Revista dos Tribunais, 2015.

OIT. Empregos verdes: Rumo ao trabalho decente em um mundo sustentável e com baixas emissões de carbono. Brasília, Escritório da OIT no Brasil, 2008.

OIT. Le programme de l'OIT pour les emplois verts. Description de l'organisation. Genebra: Oficina Internacional do Trabalho, 2016. Disponível em: http://www. ilo.org/global/topics/green-jobs/WCMS_344815/lang--fr/index.htm. Acesso em: 31/08/2016.

OIT. Promover la seguridad y la salud en una economía verde. Genebra: Oficina Internacional del $\quad 2012 . \quad$ Trabajo, Disponível em: http://www.ilo.org/wcmsp5/groups/public/@ed_protect/@protrav/@safework/documents/pres entation/wcms_178180.pdf. Acesso em: 17/07/2016.

OIT. Hacia el desarrollo sostenible: Oportunidades de trabajo decente e inclusión social en una economía verde. Genebra: Oficina Internacional del Trabajo, 2012a. Disponível em: http://www.ilo.org/wcmsp5/groups/public/---dgreports/---dcomm/---

publ/documents/publication/wcms_181392.pdf. Acesso em: 17/10/2016.ONU. Nosso futuro comum. 2 ed. Rio de Janeiro: Fundação Getúlio Vargas, 1991.

SOUTO MAIOR, Jorge Luiz; CORREIA, M.O.G. O que é direito social? In: CORREIA, Marcus Orione Gonçalves (Org.). Curso de Direito do Trabalho. São Paulo: LTr, 2007, p. 1140 . 